\title{
Dedifferentiated peripheral chondrosarcomas: regulation of EXT-downstream molecules and differentiation-related genes
}

\author{
Leida B Rozeman ${ }^{1}$, Inge H Briaire de Bruijn ${ }^{1}$, Patrizia Bacchini ${ }^{2}$, Eric L Staals ${ }^{3}$, \\ Franco Bertoni ${ }^{2}$, Judith VMG Bovée ${ }^{1}$ and Pancras CW Hogendoorn ${ }^{1}$ \\ ${ }^{1}$ Department of Pathology, Leiden University Medical Center, Leiden, The Netherlands; ${ }^{2}$ Department of \\ Surgical Pathology, Instituto Ortopedico, Rizzoli, Bologna, Italy and ${ }^{3}$ Fifth Orthopedic Division, Rizzoli \\ Orthopedic Institute, Bologna, Italy
}

\begin{abstract}
Dedifferentiated peripheral chondrosarcoma is a rare subtype of chondrosarcoma arising superimposed on the cartilage cap of a preexisting osteochondroma. It consists of two clearly defined components, a low-grade malignant, well-differentiated cartilage component and a high-grade non-cartilaginous sarcoma. Signaling pathways having a role in normal cartilage development were analyzed in these tumors, and compared with available data of other cartilaginous tumors. Sixteen well-characterized dedifferentiated peripheral chondrosarcomas were immunohistochemically analyzed for parathyroid hormone-like hormone (PTHLH)-BCL-2, fibroblastic growth factor (FGF), and transforming growth factor- $\beta$ signaling molecules, as well as matrix molecules and p53, comparing the chondrogenic component of dedifferentiated peripheral chondrosarcomas with the anaplastic component and with previously published data obtained from conventional grade I and II secondary peripheral chondrosarcomas. Results were correlated with clinical outcome. In the anaplastic component, various lines of differentiation could be found (collagen I (6/16), CD31 (1/16), smooth muscle actin $(12 / 16)$, muscle-specific actin (12/16) and desmin (2/9)). Compared with the anaplastic component, the chondrogenic component of dedifferentiated peripheral chondrosarcomas shows more often expression of cyclin D1 $(P=0.05)$, p53 $(P=0.008)$, plasminogen activator inhibitor $1(\mathrm{PAl}-1)(P=0.005)$, and CD44 $(P=0.030)$. Compared with secondary peripheral chondrosarcomas, more samples were positive in the chondrogenic component of dedifferentiated peripheral chondrosarcomas for FGF signaling (FGF receptor $3 \boldsymbol{P}=\mathbf{0 . 0 0 0}$; $\mathrm{bFGF}$ $P=0.003)$ and CD44 $(P=0.000)$. Lower expression of BCL-2 $(P=0.025)$ and absence of CD44v3 $(P=0.000)$, a splice variant of $\mathrm{CD} 44$, was observed in the chondrogenic component of dedifferentiated peripheral chondrosarcomas compared with secondary peripheral chondrosarcomas. With regard to clinical data, PAl-1 expression in the chondrogenic component of dedifferentiated peripheral chondrosarcomas correlated with better survival $(P=0.019)$. In conclusion, in the chondrogenic component of dedifferentiated peripheral chondrosarcomas, FGF signaling pathway is active, whereas PTHLH signaling seems to be low/downregulated. Interestingly, although the chondrogenic component of dedifferentiated peripheral chondrosarcoma is CD44 + I CD44v3-, secondary peripheral chondrosarcomas is CD44-/CD44v3 + , which suggest different splicing (preference). The prognostic value of PAI-1 in dedifferentiated peripheral chondrosarcomas might also be of interest for the more common dedifferentiated central chondrosarcomas.

Modern Pathology (2009) 22, 1489-1498; doi:10.1038/modpathol.2009.120; published online 4 September 2009
\end{abstract}

Keywords: bone neoplasm; osteochondroma; chondrosarcoma; dedifferentiated chondrosarcoma; cell signaling

Correspondence: Professor PCW Hogendoorn, MD, PhD, Department of Pathology, Leiden University Medical Center, L1-Q, PO Box 9600, Albinusdreef 2, Leiden 2300RC, The Netherlands.

E-mail: p.c.w.hogendoorn@lumc.nl

Received 20 April 2009; revised and accepted 1 July 2009; published online 4 September 2009
Most chondrosarcomas are well-differentiated conventional low-grade tumors, either arising centrally in the bone (central chondrosarcomas) or at the periphery, secondary to osteochondroma (secondary peripheral chondrosarcomas). ${ }^{1}$ About $10 \%$ of the chondrosarcomas are dedifferentiated chondrosarcomas, nearly exclusively of the central subtype. ${ }^{2}$ 


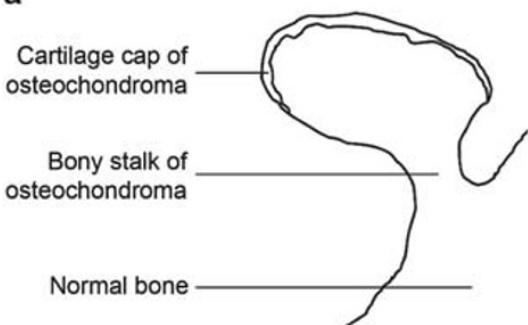

b

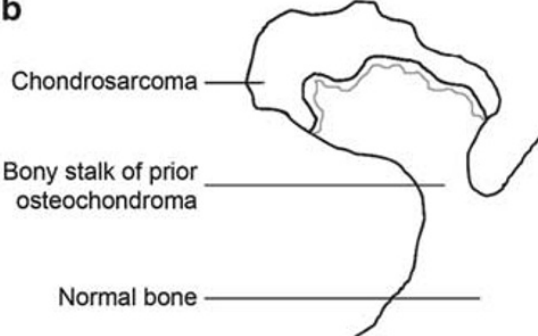

Secondary

d

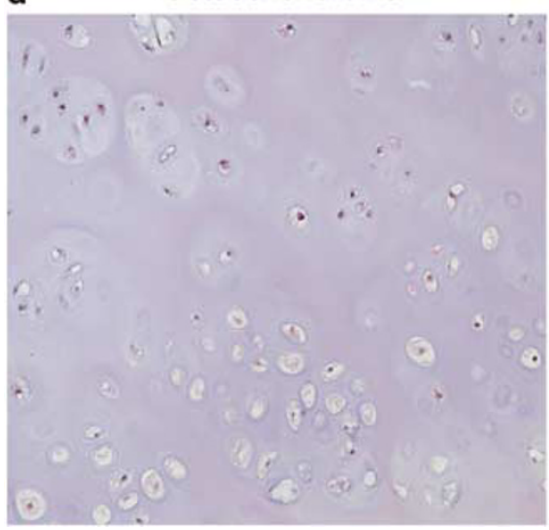

e peripheral chondrosarcoma

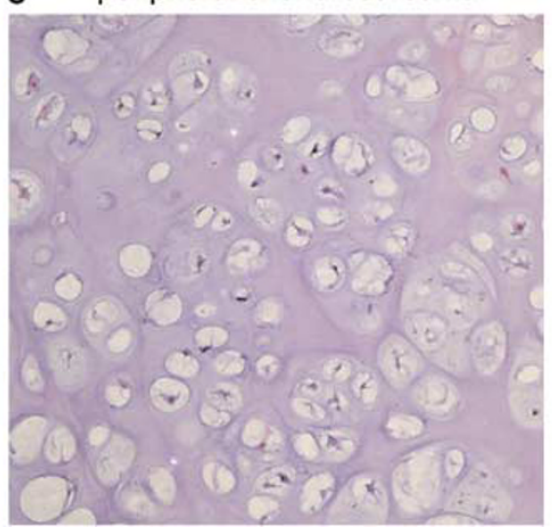

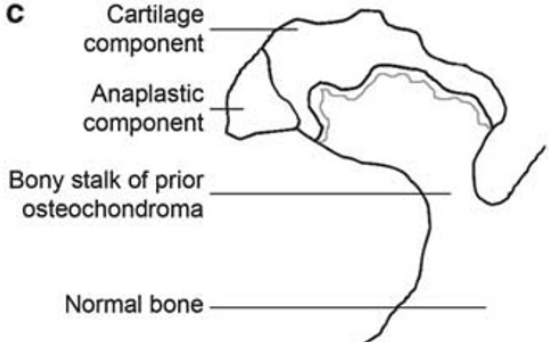

Dedifferentiated f peripheral chondrosarcoma

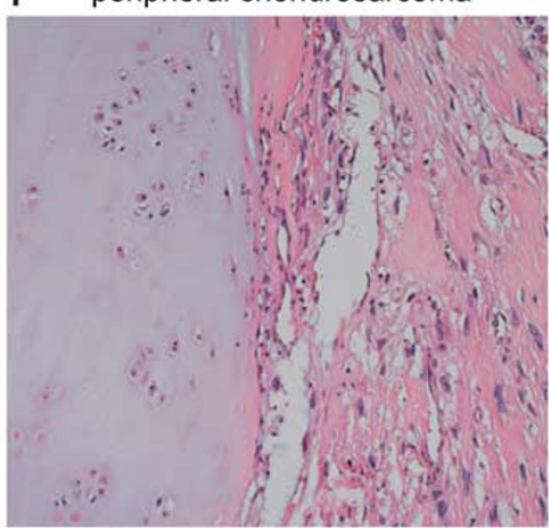

Figure 1 Schematics of dedifferentiation development and the associated features. The difference and development of the osteochondroma (a, H\&E in d) to chondrosarcoma (b, H\&E in e) and to dedifferentiated chondrosarcoma (c, H\&E in f). Note the sharp border between the chondrogenic and anaplastic component of the dedifferentiated chondrosarcoma in $\mathbf{f}$.

The very small proportion consisting of peripheral dedifferentiated chondrosarcomas arise from lowgrade chondrosarcomas originating from the cartilage cap of a preexisting benign osteochondroma (Figure $1 \mathrm{a}-\mathrm{C}) .^{3}$ Osteochondroma is a benign bony outgrowth covered by a cartilaginous cap, of which the solitary sporadic form is about six times more common than the occurrence within the context of multiple osteochondromas. Multiple osteochondromas (previously known as hereditary multiple exostoses) is an autosomal dominant disorder. In both solitary and multiple osteochondromas, the EXT1 and/or EXT2 genes are affected on the genomic level, by mutation and/or deletions. ${ }^{4,5}$

The incidence of dedifferentiated peripheral chondrosarcomas is not very well documented, but from the two largest available series (Mayo clinic, Rochester, MN, USA and Rizzoli Institute, Bologna, Italy) the percentage of dedifferentiated peripheral chondrosarcomas among all dedifferentiated chondrosarcomas is $3.8^{6}$ and $5.5 \%,{ }^{7}$ respectively. Currently, 49 cases of dedifferentiated peripheral chondrosarcomas have been reported in literature, of which 20 occurred in patients with multiple osteochondromas. ${ }^{3,7-20}$

Dedifferentiated chondrosarcomas consist of two clearly defined components, a low-grade, welldifferentiated cartilage tumor (low-grade peripheral chondrosarcoma in the case of a dedifferentiated peripheral chondrosarcomas) and juxtaposed a high-grade non-cartilaginous sarcoma. The transi- tion between these tumor components is histologically abrupt ${ }^{2,21}$ (Figure 1f).

Dedifferentiated chondrosarcoma is very aggressive and consequently the prognosis is poor. ${ }^{22}$ Metastases are frequently present at diagnosis or are found within 2 years of the diagnosis. The overall 2-year survival is $\sim 38 \%$ and 5 -year survival is $\sim 24 \%$, but only $10 \%$ of the patients with distant metastasis at diagnosis survive for 2 years. ${ }^{23}$ Most of these tumors are resistant to chemotherapy. ${ }^{24-26}$

Little information is known about the molecular characterization of dedifferentiated chondrosarcomas. It was shown that central dedifferentiated chondrosarcomas have a monoclonal origin, with an early diversion into the two tumor components. ${ }^{27}$ Protein expression studies have been carried out on only a limited number of samples (ranging from 2 to 15 samples, irrespective of the central/peripheral location). ${ }^{28-32}$

The aim of this study was to elucidate the line of differentiation, if present, of the anaplastic component of dedifferentiated peripheral chondrosarcomas. Further, we studied fibroblastic growth factor (FGF), parathyroid hormone-like hormone (PTHLH), and transforming growth factor beta (TGF- $\beta$ ) cellsignaling pathways that are known to have an important role in normal chondrocyte proliferation and differentiation and that are hypothesized to be affected by inactivated EXT, in both the chondrogenic and anaplastic component of dedifferentiated peripheral chondrosarcomas. 


\section{Materials and methods}

\section{Patient Samples}

Patient charts, histological slides, and radiographs were available at the Rizzoli Institute in Bologna; 14 patients were treated at the Rizzoli Institute, and 2 patients were referred to the Rizzoli Institute for consultation. The samples were part of a study in which the clinical data were published previously. ${ }^{7}$ Patient details can be found in Table 1. All tissue samples were handled in a coded fashion, according to the Dutch National Ethical Guidelines ('Code for Proper Secondary Use of Human Tissue', Dutch Federation of Medical Scientific Societies). The slides were reviewed by three bone tumor pathologists (FB, JVMGB, and PCWH).

\section{Immunohistochemistry}

Immunohistochemistry was carried out on all cases, as described previously. ${ }^{33}$ Details can be found in Table 2. Immunohistochemical staining for musclespecific actin, smooth muscle actin, desmin, collagen type 1 (Col I), and CD31 (angiogenic marker) was used to determine a line of differentiation of the anaplastic component (osteogenic-like, myo(fibro)blastic, or angiogenic) in dedifferentiated peripheral chondrosarcomas. PTHLH signaling was studied using immunohistochemistry for PTHLH, PTH receptor 1 (PTHR1), BCL-2, and cyclin D1. For FGF signaling, fibroblastic growth factor receptor 3 (FGFR3) and bFGF (also known as FGF2) were stained. TGF- $\beta$ signaling was investigated using TGF- $\beta$ and plasminogen activator inhibitor 1 (PAI-1) expression. CD44, a cell surface glycoprotein, and CD44v3, an oncogenic splice variant of CD44 carrying a heparan sulphate proteoglycan (HSPG) side chain, were investigated. Scoring was performed as described. ${ }^{33}$ The chondrogenic and anaplastic component were evaluated separately. In brief, staining intensities ( $0=$ negative, $1=$ weak, $2=$ moderate, and $3=$ strong intensity) and percentage of positive cells $(0=0 \%, 1=1-24 \%, 2=25-$ $49 \%, 3=50-74 \%$, and $4=75-100 \%$ positive) or in case of collagen type I staining distribution ( $1=$ focal and $2=$ diffuse) were assessed. The samples were scored positive if the combined values of staining intensity and percentage of positive cells or staining distribution were $>3$ for PTHLH, PTHR1, BCL-2, p53, FGFR3, bFGF, TGF- $\beta$, PAI-1, and Col I, and $>0$ for cyclin D1, muscle-specific actin, smooth muscle actin, desmin, CD31, CD44, and CD44v3, as previously published. ${ }^{33-35}$

\section{Meta-analysis}

Results of this study were compared with previously published results on a series of 44 secondary peripheral chondrosarcomas grade I and II. ${ }^{33-35}$

\section{Statistical Analysis}

Statistical analysis was carried out using SPSS 14.0.1. Statistical significance was defined as $P<0.05$.

\section{Results}

\section{Patient Population Description}

The patient group consisted of 12 males and 4 females with a mean age of 43.4 years at diagnosis (range 2274 years), of which clinical details were described previously. ${ }^{7}$ All tumors were both histologically and radiologically proven to originate from a preexisting osteochondroma (for details see Table 1).

\section{Immunohistochemical Analysis}

Expression of differentiation-related molecules Thirteen out of sixteen dedifferentiated peripheral chondrosarcomas showed myo(fibro)blastic differentiation of the anaplastic component, as was shown by expression of muscle-specific actin and/ or smooth muscle actin and the absence of CD31 (two positive for SMA, MSA, and collagen type I; one positive for muscle-specific actin, smooth muscle actin, and desmin; eight positive for muscle-specific actin and smooth muscle actin; one positive for muscle-specific actin and collagen type I; one positive for only smooth muscle actin). The two tumors showing osteogenic differentiation, as determined by examination of the $H \& E$ section were negative for muscle-specific actin, smooth muscle actin, and CD31 (one was positive for collagen type I and desmin, one positive for only collagen type I). One dedifferentiated peripheral chondrosarcoma displayed angiogenic differentiation of the anaplastic component as shown by the expression of CD31 (positive for collagen type I and CD31). Results are summarized in Tables 1 and 3 .

\section{Expression of signaling pathway molecules}

Dedifferentiated peripheral chondrosarcomas showed the expression of FGF signaling molecules in $92-100 \%$ of the tumors, both in the chondrogenic as well as in the anaplastic component. In contrast, expression was only found in up to one-third of conventional secondary peripheral chondrosarcomas. In addition, PTHLH signaling differed between dedifferentiated peripheral chondrosarcomas and conventional secondary peripheral chondrosarcoma; expression of BCL-2 was remarkably absent in dedifferentiated peripheral chondrosarcomas, although found in over half of the secondary peripheral chondrosarcomas $(P=0.025$, Fisher's exact test). The cell surface protein CD44, which was absent in secondary peripheral chondrosarcoma, was found in the chondrogenic component of 9 of 13 dedifferentiated peripheral chondrosarcomas 
Table 1 Clinicopathological data

\begin{tabular}{|c|c|c|c|c|c|c|c|c|c|c|c|c|}
\hline $\begin{array}{l}\text { Patient } \\
\text { no. }\end{array}$ & $M / F$ & $\begin{array}{c}\text { Age } \\
\text { (years) }\end{array}$ & $M O$ & $\begin{array}{l}\text { Chondro- } \\
\text { genic } \\
\text { comp }\end{array}$ & $\begin{array}{l}\text { Anaplastic } \\
\text { comp }^{\mathrm{a}}\end{array}$ & $\begin{array}{l}\% \\
\text { anapl. } \\
\text { comp. }\end{array}$ & Stage & $\begin{array}{l}\text { Initial } \\
\text { treatment }\end{array}$ & $\begin{array}{l}\text { Additional } \\
\text { treatment }\end{array}$ & $\begin{array}{l}\text { Clinical } \\
\text { outcome }\end{array}$ & $\begin{array}{l}\text { Follow-up } \\
\text { (months) }\end{array}$ & Outcome \\
\hline 1 & M & 26 & Yes & CS I & Myo(fibro) & 20 & IIB & $\begin{array}{l}\text { Resection+postop } \\
\text { CHT }\end{array}$ & & DOD & 13 & $\begin{array}{l}\text { Month 4: lung mets, dead } \\
\text { with lung mets }\end{array}$ \\
\hline 2 & M & 43 & & CS II & Myo(fibro) & 20 & IIIB & Resection & & DOD & 12 & $\begin{array}{l}\text { Month 1: lung mets, dead of } \\
\text { mets }\end{array}$ \\
\hline 3 & $\mathrm{~F}$ & 74 & & CS II & Myo(fibro) & 90 & IIB & Resection & & DOD & 3 & $\begin{array}{l}\text { No mets at presentation, dead } \\
\text { of mets }\end{array}$ \\
\hline 4 & M & 35 & Yes & CS II & Myo(fibro) & 60 & IIB & $\begin{array}{l}\text { Resection+postop } \\
\text { CHT }\end{array}$ & & NED & 123 & \\
\hline 5 & M & 53 & Yes & - & Myo(fibro) & - & IIIB & $\begin{array}{l}\text { bx (no further } \\
\text { treatment, lung } \\
\text { mets) }\end{array}$ & & DOD & 6 & Lung mets at diagn (st III) \\
\hline 6 & $\mathrm{~F}$ & 29 & & CS II & Myo(fibro) & 30 & IIB & Resection & $\begin{array}{l}\text { Month 43: bone } \\
\text { mets: } \\
\text { RxT }\end{array}$ & DOD & 51 & $\begin{array}{l}\text { Month } 40 \text { : lung mets, month } \\
44: \text { bone mets, } \\
\text { dead of mets }\end{array}$ \\
\hline 7 & $\mathrm{~F}$ & 22 & & - & Angio & 100 & IIB & Excision & $\begin{array}{l}\text { Month 10: LR+mets } \\
\text { bx, } \\
\text { surg excision+CHT }\end{array}$ & DOD & 28 & $\begin{array}{l}\text { Month 10:LR+mets, month } \\
\text { 19:brain mets, } \\
\text { dead with lung+brain mets }\end{array}$ \\
\hline 8 & M & 34 & & CS I & Myo(fibro) & 60 & IIB & Above knee amp & $\begin{array}{l}\text { Month } 7 \text { : lung } \\
\text { mets: excision }\end{array}$ & DOD & 14 & $\begin{array}{l}\text { Month 7: lung mets, dead } \\
\text { with lung mets }\end{array}$ \\
\hline 9 & $\mathrm{~F}$ & 22 & Yes & CS II & Myo(fibro) & 60 & IIB & $\begin{array}{l}\text { Resection+postop } \\
\text { CHT }\end{array}$ & & NED & 97 & \\
\hline 10 & M & 40 & Yes & CS I & Myo(fibro) & 30 & IIB & $\begin{array}{l}\text { Hindquarter } \\
\text { amp+postop CHT }\end{array}$ & & NED & 97 & \\
\hline 11 & M & 68 & & CS I & Osteo & 80 & IIB & $\begin{array}{l}\text { Above knee amp+ } \\
\text { postop CHT }\end{array}$ & & NED & 22 & \\
\hline 12 & $\mathrm{M}$ & 67 & Yes & CS I & Osteo & 95 & IIIB & Above knee amp & & DOD & 9 & Lung mets at diagn (st III) \\
\hline 13 & M & 39 & Yes & - & Myo(fibro) & 100 & IIB & Above knee amp & & DOD & 4 & $\begin{array}{l}\text { No mets at presentation, dead } \\
\text { of lung mets }\end{array}$ \\
\hline 14 & M & 41 & & CS I & Myo(fibro) & 60 & IIB & $\begin{array}{l}\text { Resection+postop } \\
\text { CHT }\end{array}$ & & NED & 80 & \\
\hline 15 & $\mathrm{M}$ & 54 & & CS I & Myo(fibro) & - & - & & & - & - & \\
\hline 16 & M & 48 & Yes & CS I & Myo(fibro) & - & - & bx & & - & - & \\
\hline
\end{tabular}

Abbreviations: amp, amputation; angio, angiogenic differentiation; bx, diagnostic biopsy; CHT, chemotherapy; Comp, component; DOD, death of disease; F, female; LR, local recurrence; M, male; mets, metastases; myo(fibro), myofibroblastic differentiation; NED, no evidence of disease; osteo, osteogenic differentiation; postop, postoperative; RxT, radiotherapy.

${ }^{a}$ Anaplastic component as derived from immunohistochemical stainings of differentiation-related molecules. 
Table 2 Details of antibodies used for immunohistochemistry

\begin{tabular}{|c|c|c|c|c|c|}
\hline Antigen (clone) & Manufacturer & Mono/polyclonal & Positive control & Dilution & $\begin{array}{l}\text { Antigen } \\
\text { retrieval }\end{array}$ \\
\hline FGFR3 & $\begin{array}{l}\text { Sigma-Aldrich (Zwijndrecht, } \\
\text { The Netherlands) }\end{array}$ & $\mathrm{P}$ & Umbilical cord & $1: 3000$ & Trypsin \\
\hline bFGF & $\begin{array}{l}\text { BD Transduction laboratories } \\
\text { (Erembodegem, Belgium) }\end{array}$ & M & Skin & $1: 150$ & Citrate \\
\hline PTHLH & Oncogene (San. Diego, CA, USA) & $\mathrm{P}$ & Skin & $1: 150$ & Trypsin \\
\hline PTHR1 & $\begin{array}{l}\text { Upstate biotechnologies (Lake } \\
\text { Placid, NY, USA) }\end{array}$ & $\mathrm{M}$ & Skin & $1: 100$ & Citrate \\
\hline Cyclin D1 (SP4) & Neomarkers (Fremont, CA, USA) & $\mathrm{P}$ & Tonsil & $1: 75$ & Citrate \\
\hline BCL-2 (124) & DAKO (Heverlee, Belgium) & $\mathrm{M}$ & Tonsil & $1: 150$ & Citrate \\
\hline P53 (DO-7) & Neomarkers (Fremont, CA, USA) & $\mathrm{M}$ & Colorectal carcinoma & $1: 4000$ & Citrate \\
\hline $\mathrm{TGF} \beta$ & $\begin{array}{l}\text { Department of Pathology, LUMC } \\
\text { (Leiden, The Netherlands) }\end{array}$ & $\mathrm{P}$ & $\begin{array}{l}\text { Breast } \\
\text { carcinoma }\end{array}$ & $1: 800$ & Citrate \\
\hline PAI-1 & $\begin{array}{l}\text { American diagnostica (Stamford, } \\
\text { CT, USA) }\end{array}$ & $\mathrm{M}$ & Breast carcinoma & $1: 350$ & - \\
\hline CD44 (F10-44-2) & $\begin{array}{l}\text { Monosan (Uden The } \\
\text { Netherlands) }\end{array}$ & M & Tonsil & $1: 100$ & Citrate \\
\hline CD44v3 (VFF-327V3) & $\begin{array}{l}\text { Novo castra (Newcastle Upon } \\
\text { Tyne, UK) }\end{array}$ & $\mathrm{M}$ & Tonsil & $1: 400$ & Citrate \\
\hline COL I & Kindly provided ${ }^{a}$ & $\mathrm{P}$ & Skin & $1: 3000$ & Citrate \\
\hline CD31 & DAKO (Heverlee, Belgium) & $\mathrm{M}$ & Tonsil & $1: 75$ & Citrate \\
\hline SM actin (ASM-1) & Progen (Heidelberg, Germany) & $\mathrm{M}$ & Colon & $1: 4000$ & - \\
\hline MSA & DAKO (Heverlee, Belgium) & $\mathrm{M}$ & Colon & $1: 2000$ & - \\
\hline Desmin & $\begin{array}{l}\text { Department of Pathology, LUMC } \\
\text { (Leiden, The Netherlands) }\end{array}$ & $\mathrm{P}$ & Colon & $1: 150$ & - \\
\hline
\end{tabular}

M, monoclonal; MSA, muscle-specific actin; P, polyclonal; SM actin, smooth muscle actin.

${ }^{\mathrm{a}}$ Kindly provided by the Department of Endocrinology, Leiden University Medical Center.

Table 3 Immunohistochemical results: dedifferentiation-related molecules

Protein Dedifferentiated peripheral chondrosarcoma P-value

\begin{tabular}{lcrl} 
& Chondrogenic & Anaplastic & \\
\cline { 2 - 3 } & & & \\
COL I & $3 / 10(10 \%)$ & $6 / 16(38 \%)$ & 1.00 \\
CD31 & - & $1 / 16(6 \%)$ & \\
SM actin & - & $12 / 16(75 \%)$ & \\
MSA & - & $12 / 16(75 \%)$ & \\
Desmin & - & $2 / 9(22 \%)$ & \\
& & &
\end{tabular}

MSA, muscle-specific actin; SM actin, smooth muscle actin.

${ }^{\text {a }} P$-value (Fisher's exact test) from the comparison of the chondrogenic component with the anaplastic component of the dedifferentiated peripheral chondrosarcomas; $-=$ negative.

(69\%) $(P=0.000$, Fisher's exact test $)$ and in the anaplastic component of all dedifferentiated peripheral chondrosarcomas (100\%). In contrast, the exon 3 containing splice variant CD44v3 (a heparan sulphate side chain containing variable) was more frequently found in conventional secondary peripheral chondrosarcoma $(97 \%)$ as compared with the chondrogenic component of dedifferentiated peripheral chondrosarcomas $(11 \%) \quad(P=0.000$, Fisher's exact test, Figure 2d).

As compared with the chondrogenic component, the anaplastic component of dedifferentiated peripheral chondrosarcomas shows increased expression of CD44 $(P=0.030$, Fisher's exact test, Figure 2c), cyclin D1 ( $P=0.050$; Fisher's exact test,
Figure 2a), p53 $(P=0.008$, Fisher's exact test, Figure 2b), and PAI-1 ( $P=0.005$, Fisher's exact test, Figure $3 \mathrm{a}$ and $\mathrm{b}$, Table 4).

\section{Correlation with patient outcome}

PAI-1 expression in the chondrogenic component was the only staining with prognostic value $(P=0.019$, univariate log-rank Mantel Cox test, Figure 3). Although numbers are small, our data suggest that patients with absence of PAI-1 expression in the chondrogenic component have an increased risk on metastasis and subsequent death.

\section{Discussion}

Dedifferentiated chondrosarcomas are rare, and comprise $\sim 10 \%$ of all chondrosarcomas. ${ }^{2}$ Interestingly, of all dedifferentiated chondrosarcomas, only $\sim 3.8-5.5 \%$ is of the peripheral subtype.$^{6,7}$ This is much lower than one would estimate on the basis of the frequency of secondary peripheral chondrosarcomas, which comprise of $\sim 17 \%$ of all conventional chondrosarcomas. This emphasizes that dedifferentiation is a rare event in peripheral chondrosarcoma as compared with central chondrosarcoma. The reason for this lower rate of dedifferentiation in peripheral chondrosarcoma remains unclear.

In the past it was unclear whether conventional secondary peripheral chondrosarcomas could develop into dedifferentiated chondrosarcomas, similar to its central counterpart. Currently, sufficient evidence 

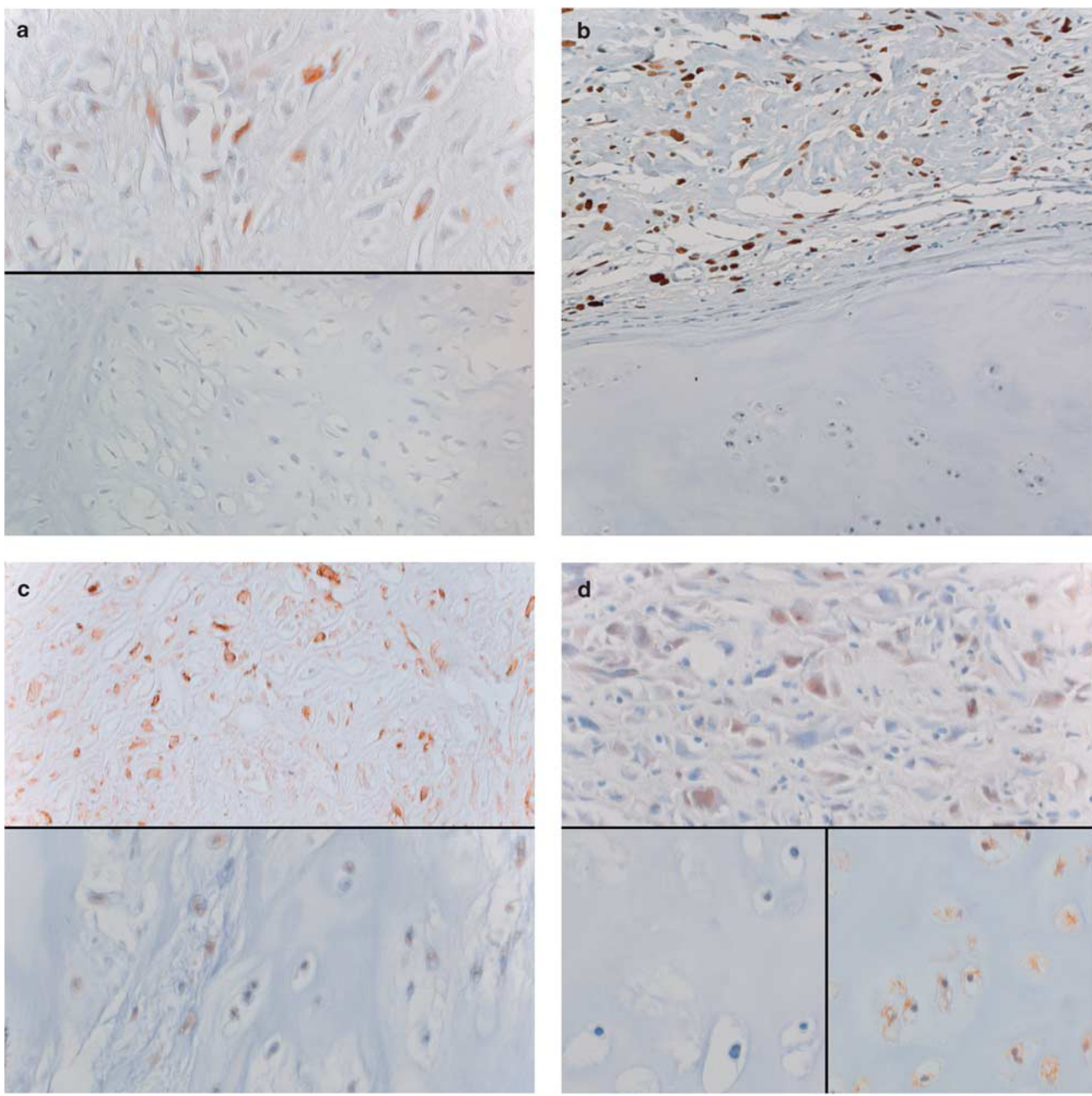

Figure 2 Immunohistochemical stainings. Higher expression of cyclin D1 (a), p53 (b), and CD44 (c) is observed in the anaplastic component of the dedifferentiated peripheral chondrosarcomas (top) compared with the chondrogenic component of the dedifferentiated peripheral chondrosarcomas. CD44v3 (d) is expressed in the anaplastic component of the dedifferentiated peripheral chondrosarcomas (top), but almost always absent or very less expressed in the chondrogenic component of the dedifferentiated peripheral chondrosarcomas (bottom left), in contrast to the CD44v3 expression in conventional peripheral chondrosarcomas (bottom right).

has been proposed to support that this may happen on rare occasions. ${ }^{3,7-20}$ It is sometimes difficult to rule out the possibility that another second malignancy is found in an osteochondroma. ${ }^{36-40}$

In our series of 16 dedifferentiated peripheral chondrosarcomas, we show that the anaplastic component most often displays myo(fibro)blastic differentiation in its so-called dedifferentiated component, as could be determined from the musclespecific actin and smooth muscle actin staining. It is important to realize that the anaplastic component can also show desmin positivity, as we found in 2 of 16 cases, to avoid confusion with leiomyosarcoma in the diagnostic practice. Interestingly, although in dedifferentiated peripheral chondrosarcomas, myofibroblastic differentiation is most common in the anaplastic component, in dedifferentiated central chondrosarcomas the majority of the anaplastic components is of the so-called osteogenic subtype. ${ }^{25}$ The line of differentiation within the anaplastic component is important, as the anaplastic component determines the clinical behavior and therefore 

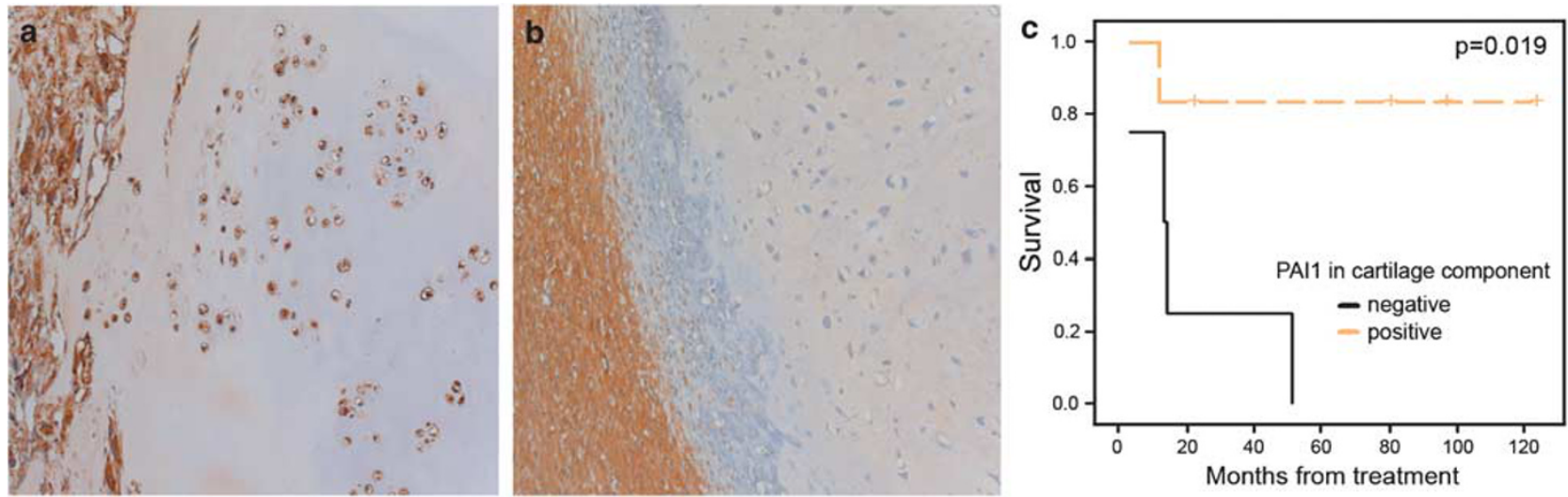

Figure 3 PAI-1 expression in the chondrogenic component correlates with prognosis. PAI-1 expression is high in the cartilaginous component of dedifferentiated peripheral chondrosarcomas (sample 14) with good prognosis (a) compared with low PAI-1 expression in the chondrogenic component of dedifferentiated peripheral chondrosarcoma (sample 3) with poor prognosis (b). (c) Expression of PAI-1 in the chondrogenic component of dedifferentiated peripheral chondrosarcomas correlates with survival (PAI-1 negative, $n=4$; PAI-1 positive, $n=6$, Kaplan-Meier, log-rank (Mantel-Cox)).

Table 4 Immunohistochemical results: signaling pathway molecules

\begin{tabular}{|c|c|c|c|c|c|}
\hline \multirow[t]{2}{*}{ Protein } & \multicolumn{2}{|c|}{ Dedifferentiated peripheral chondrosarcoma } & \multirow[t]{2}{*}{ P-value ${ }^{\mathrm{a}}$} & \multirow{2}{*}{$\begin{array}{l}\text { Secondary peripheral } \\
\text { chondrosarcoma }\end{array}$} & \multirow[t]{2}{*}{$\mathrm{P}$-value ${ }^{\mathrm{b}}$} \\
\hline & Chondrogenic & Anaplastic & & & \\
\hline \multicolumn{6}{|c|}{$F G F$ signaling } \\
\hline FGFR3 & $10 / 10(100 \%)$ & $15 / 15(100 \%)$ & - & $5 / 22(23 \%)$ & 0.000 \\
\hline bFGF & $11 / 12(92 \%)$ & $16 / 16(100 \%)$ & 0.429 & $7 / 21(33 \%)$ & 0.003 \\
\hline \multicolumn{6}{|c|}{ PTHLH signaling } \\
\hline PTHLH & $5 / 9(56 \%)$ & 7/12 (58\%) & 1.00 & $23 / 29(79 \%)$ & 0.205 \\
\hline PTHR1 & $1 / 6(17 \%)$ & $3 / 8(38 \%)$ & 0.580 & $8 / 20(40 \%)$ & 0.380 \\
\hline Cyclin D1 & $1 / 7(14 \%)$ & $8 / 11(73 \%)$ & 0.050 & nd & \\
\hline BCL-2 & $0 / 7(0 \%)$ & $0 / 15(0 \%)$ & - & $13 / 24(54 \%)$ & 0.025 \\
\hline \multicolumn{6}{|c|}{ TGF- $\beta$ signaling } \\
\hline TGF- $\beta$ & $12 / 12(100 \%)$ & $16 / 16(100 \%)$ & - & nd & \\
\hline PAI-1 & $6 / 11(55 \%)$ & $16 / 16(100 \%)$ & 0.005 & $27 / 36(75 \%)$ & 0.263 \\
\hline \multicolumn{6}{|c|}{ CD44 signaling } \\
\hline $\mathrm{CD} 44$ & $9 / 13(69 \%)$ & $16 / 16(100 \%)$ & 0.030 & $0 / 28(0 \%)$ & 0.000 \\
\hline CD44v3 & $1 / 9(11 \%)$ & $3 / 15(20 \%)$ & 1.00 & $36 / 37(97 \%)$ & 0.000 \\
\hline \multicolumn{6}{|c|}{ Apoptosis signaling } \\
\hline p53 & $0 / 8(0 \%)$ & 10/13 (77\%) & 0.008 & 6/17 (35\%) & 0.362 \\
\hline
\end{tabular}

nd, not done.

${ }^{a} P$-value (Fisher's exact test) from the comparison of the chondrogenic component with the anaplastic component of the dedifferentiated peripheral chondrosarcomas.

${ }^{\mathrm{b}} P$-value (Fisher's exact test) from the comparison of the chondrogenic component of dedifferentiated peripheral chondrosarcomas with secondary peripheral chondrosarcomas grade I and II.

Bold values are significant $P$-values $(P<0.05)$.

guides possible choices of chemotherapy or future targeted therapy.

In peripheral chondrosarcomas, the EXT1 and/or EXT2 genes are affected on the genomic level, by mutation and/or deletions, ${ }^{4,5}$ leading to aberrant HSPG synthesis. ${ }^{41}$ HSPGs are involved in signal transduction of several pathways, including the hedgehog, TGF- $\beta$, and FGF signaling. ${ }^{42,43}$ We studied the expression of growth plate signaling molecules in the PTHLH-BCL-2, FGF, and TFG- $\beta$ signaling pathways, which have been extensively studied in other cartilaginous tumors. ${ }^{34-36,44-47}$ In addition, the expression of matrix molecules was studied and the expression in the two components was compared. These signaling molecules have an important role in the growth and differentiation of the normal growth plate and could therefore be of importance in the cartilaginous tumor development and tumor progression. For instance, expression of PTHLH and BCL-2 was found to be of diagnostic value in the 
distinction between osteochondroma and low-grade secondary peripheral chondrosarcoma, with low or absent expression in the osteochondromas. ${ }^{44}$

Differences in expression between the chondrogenic and anaplastic component were found in molecules related to cell cycle regulation (cyclin D1) and p53 (apoptosis). Upregulation of the cell cycle in the anaplastic component is to be expected, as this component is highly active with more mitoses present compared with the chondrogenic component. In addition, the upregulation of p53, most likely a mutated, inactive form is often seen in high-grade tumors, as is also observed previously in high-grade chondrosarcomas and dedifferentiated chondrosarcomas (reviewed in Rozeman et al. ${ }^{28}$ )

Comparison of the chondrogenic component of the peripheral dedifferentiated chondrosarcomas with the secondary peripheral chondrosarcomas grade I and II, which match the stage of the chondrogenic component found in dedifferentiated chondrosarcomas, revealed some interesting differences. In the dedifferentiated chondrogenic component, the FGF signaling is higher, ${ }^{33}$ as well as the CD44 expression. ${ }^{35}$ On the other hand, expressions of PTHLH, BCL-2, p53, and CD44v3 are low. ${ }^{3-35,44}$ The higher expression of the FGF signaling and altered expression status of CD44/CD44v3, when comparing the chondrogenic component of dedifferentiated peripheral chondrosarcomas with conventional secondary peripheral chondrosarcomas, suggests that these changes maybe of importance in the transformation of chondrosarcoma toward dedifferentiated chondrosarcoma, which unfortunately is canceled out by the anaplastic component.

Increased PAI-1 expression in the anaplastic component as seen in this paper was also observed previously in conventional dedifferentiated chondrosarcomas. ${ }^{48}$ It is interesting that the expression of PAI1 in the cartilaginous component of dedifferentiated peripheral chondrosarcomas is related to good prognosis, although these are small numbers. PAI-1 is partly regulated by TGF- $\beta .^{49,50}$ PAI-1 has many functions in the cell and is able to influence cell motility in several ways, such as by binding to the adhesive glycoprotein vitronectin and detaching cells from (a variety of) matrix proteins by inducing the internalization of adhesion receptors. ${ }^{51} \mathrm{PAI}-1$ also has a role in the process of angiogenesis. ${ }^{51}$ Although at first glance the PAI-1/TGF- $\beta$ signaling might be a good candidate to start looking for therapy, one should consider that the prognostic PAI-1 expression is localized in the cartilage component, which is notoriously hard to treat, ${ }^{22}$ as there are limited ways to reach the cells in this compartment. In addition, PAI-1 is downstream of not only TGF- $\beta$ signaling but also of EGFR signaling. ${ }^{52}$ Targeting of PAI-1 by, for instance, blocking HER-1 (upstream of PAI-1) was found to be of limited success in sarcomas, such as synovial sarcomas, ${ }^{53}$ but would required further experiments in case of dedifferentiated peripheral chondrosarcomas.
The upregulation of CD44 is seen in the anaplastic component compared with the chondrogenic component of dedifferentiated chondrosarcomas. CD44 is a transmembrane glycoprotein, involved in the regulation of growth, differentiation, survival, and cell motility. ${ }^{54}$ Misregulation of CD44, resulting in expression of different splice variants, is related to poor prognosis in many cancers, ${ }^{54}$ and is also seen in high-grade secondary peripheral chondrosarcomas. ${ }^{35}$

Patients with dedifferentiated chondrosarcomas have a bad prognosis, with $\sim 62 \%$ dying within 2 years, and in case of patients with distant metastasis at diagnosis $90 \%$ die within 2 years. ${ }^{23}$ In the current patient group, all patients with distant metastasis died within 2 years of their documentation. In all, 5 of the 16 patients had no evidence of disease after the first 2 years, one of them later still developed metastasis and died. One patient was lost to followup after 22 months, but had at that time also no evidence of disease. As most data in literature are derived from conventional dedifferentiated chondrosarcoma, which are more common than peripheral dedifferentiated chondrosarcomas, ${ }^{3,6,7}$ there might be different behavior for conventional central and peripheral dedifferentiated chondrosarcomas.

In conclusion, first, differences in expression between the chondrogenic component of dedifferentiated peripheral chondrosarcoma and secondary peripheral chondrosarcoma are present, such as CD44/CD44v3 and FGF signaling, and these might provide clues in the future to which secondary peripheral chondrosarcomas can develop into dedifferentiated chondrosarcomas. Second, as expression of actin markers is present in the majority of the dedifferentiated peripheral chondrosarcomas, care should be taken to avoid misdiagnosis of, for instance, a leiomyosarcoma based on small biopsy samples. Third, a potential prognostic marker was identified, in which PAI-1 expression in the chondrogenic component of the dedifferentiated peripheral chondrosarcoma is correlated with a good prognosis. However, only a small number of samples were available and this might influence the data.

\section{Acknowledgements}

This study was financially supported by the EuroBoNeT consortium, a European Commission granted Network of Excellence (No. 018814) for studying the pathology and genetics of bone tumors, and by the Netherlands Organization for Scientific Research (ZON-MW VIDI 917-76-315 to JVMGB).

\section{Disclosure/conflict of interest}

The authors declare no conflict of interest. 


\section{References}

1 Bertoni F, Bacchini P, Hogendoorn PCW. Chondrosarcoma. In: Fletcher CDM, Unni KK, Mertens F (eds). World Health Organisation Classification of Tumours. Pathology and Genetics of Tumours of Soft Tissue and Bone. IARC Press: Lyon, 2002, pp 247-251.

2 Milchgrub S, Hogendoorn PCW. Dedifferentiated chondrosarcoma. In: Fletcher CDM, Unni KK, Mertens F (eds). World Health Organization Classification of Tumours. Pathology and Genetics. Tumours of Soft Tissue and Bone. IARC Press: Lyon, 2002, pp 252-254.

3 Bertoni F, Present D, Bacchini P, et al. Dedifferentiated peripheral chondrosarcomas, a report of seven cases. Cancer 1989;63:2054-2059.

4 Bovée JVMG, Cleton-Jansen AM, Wuyts W, et al. EXTmutation analysis and loss of heterozygosity in sporadic and hereditary osteochondromas and secondary chondrosarcomas. Am J Hum Genet 1999;65:689-698.

5 Hameetman L, Szuhai K, Yavas A, et al. The role of EXT1 in non hereditary osteochondroma:identification of homozygous deletions. J Natl Cancer Inst 2007; 99:396-406.

6 Nascimento AG. USCAP 2006 Annual Meeting, Specialty Conference, Bone \& Soft Tissue Pathology, Case 4-Dedifferentiated Chondrosarcomas. 2006; http://www.uscap.org/newindex.htm?disindex01.htm. Accessed on 8 August 2009.

7 Staals EL, Bacchini P, Mercuri M, et al. Dedifferentiated chondrosarcomas arising in preexisting osteochondromas. J Bone Joint Surg Am 2007;89: 987-993.

8 Frassica FJ, Unni KK, Beabout JW, et al. Dedifferentiated chondrosarcoma: a report of the clinicopathological features and treatment of seventy-eight cases. J Bone Joint Surg Am 1986;68-A:1197-1205.

9 Matsuno T, Ichioka Y, Yagi T, et al. Spindle-cell sarcoma in patients who have osteochondromatosis. A report of two cases. J Bone Joint Surg Am 1988; 70:137-141.

$10 \mathrm{Du}$ YK, Shih HN, Wang JM, et al. Dedifferentiated chondrosarcoma arising from osteochondromatosis. A case report. Changgeng Yi Xue Za Zhi 1991;14: 130-135.

11 Mercuri M, Picci P, Campanacci L, et al. Dedifferentiated chondrosarcoma. Skeletal Radiol 1995;24: 409-416.

12 Park YK, Yang MH, Ryu KN, et al. Dedifferentiated chondrosarcoma arising in an osteochondroma. Skeletal Radiol 1995;24:617-619.

13 Kilpatrick SE, Pike EJ, Ward WG, et al. Dedifferentiated chondrosarcoma in patients with multiple osteochondromatosis: report of a case and review of the literature. Skeletal Radiol 1997;26:370-374.

14 Mitchell AD, Ayoub K, Mangham DC, et al. Experience in the treatment of dedifferentiated chondrosarcoma. J Bone Joint Surg Br 2000;82:55-61.

15 MacSweeney F, Darby A, Saifuddin A. Dedifferentiated chondrosarcoma of the appendicular skeleton: MRI-pathological correlation. Skeletal Radiol 2003; 32:671-678.

16 Ham SJ, Heeg M, van Horn JR. [Three patients with hereditary multiple exostoses and malignant degeneration of an osteochondroma located in the pelvis]. Ned Tijdschr Geneeskd 2004;148:1732-1738.

17 Littrell LA, Wenger DE, Wold LE, et al. Radiographic, $\mathrm{CT}$, and $\mathrm{MR}$ imaging features of dedifferentiated chondrosarcomas: a retrospective review of 174 de novo cases. Radiographics 2004;24:1397-1409.

18 Unni KK, Dahlin DC. Premalignant tumors and conditions of bone. Am J Surg Pathol 1979;3:47-60.

19 Radhi JM, Loewy J. Dedifferentiated chondrosarcoma with features of telangiectatic osteosarcoma. Pathology 1999;31:428-430.

20 Akahane T, Shimizu T, Isobe K, et al. Dedifferentiated chondrosarcoma arising in a solitary osteochondroma with leiomyosarcomatous component: a case report. Arch Orthop Trauma Surg 2008;128:951-953.

21 Dahlin DC, Beabout JW. Dedifferentiation of low-grade chondrosarcomas. Cancer 1971;28:461-466.

22 Gelderblom H, Hogendoorn PCW, Dijkstra SD, et al. The clinical approach towards chondrosarcoma. Oncologist 2008;13:320-329.

23 Grimer RJ, Gosheger G, Taminiau A, et al. Dedifferentiated chondrosarcoma: prognostic factors and outcome from a European group. Eur J Cancer 2007; 43:2060-2065.

24 Nooij MA, Whelan J, Bramwell VH, et al. Doxorubicin and cisplatin chemotherapy in high-grade spindle cell sarcomas of the bone, other than osteosarcoma or malignant fibrous histiocytoma: a European Osteosarcoma Intergroup Study. Eur J Cancer 2005;41:225-230.

25 Staals EL, Bacchini P, Bertoni F. Dedifferentiated central chondrosarcoma. Cancer 2006;106:2682-2691.

26 Dickey ID, Rose PS, Fuchs B, et al. Dedifferentiated chondrosarcoma: the role of chemotherapy with updated outcomes. J Bone Joint Surg Am 2004;86-A:2412-2418.

27 Bovée JVMG, Cleton-Jansen AM, Rosenberg C, et al. Molecular genetic characterization of both components of a dedifferentiated chondrosarcoma, with implications for its histogenesis. J Pathol 1999; 189:454-462.

28 Rozeman LB, Hogendoorn PCW, Bovée JVMG. Diagnosis and prognosis of chondrosarcoma of bone. Expert Rev Mol Diagn 2002;2:461-472.

29 Kunisada T, Moseley JM, Slavin JL, et al. Co-expression of parathyroid hormone-related protein (PTHrP) and PTH/PTHrP receptor in cartilaginous tumours: a marker for malignancy? Pathology 2002;34:133-137.

30 Yoshikawa H, Rettig WJ, Lane JM, et al. Immunohistochemical detection of bone morphogenetic proteins in bone and soft-tissue sarcomas. Cancer 1994;74: 842-847.

31 Bovée JVMG, Cleton-Jansen AM, Taminiau AHM, et al. Emerging pathways in the development of chondrosarcoma of bone and the implications for targeted treatment. Lancet Oncol 2005;6:599-607.

32 Kalinski T, Krueger S, Sel S, et al. Differential expression of VEGF-A and angiopoietins in cartilage tumors and regulation by interleukin-1beta. Cancer 2006;106:2028-2038.

33 Bovée JVMG, Van den Broek LJCM, Cleton-Jansen AM, et al. Up-regulation of PTHrP and Bcl-2 expression characterizes the progression of osteochondroma towards peripheral chondrosarcoma and is a late event in central chondrosarcoma. Lab Invest 2000;80:1925-1933.

34 Hameetman L, Rozeman LB, Lombaerts M, et al. Peripheral chondrosarcoma progression is accompanied by decreased Indian Hedgehog (IHH) signalling. J Pathol 2006;209:501-511.

35 Hameetman L, David G, Yavas A, et al. Decreased EXT expression and intracellular accumulation of HSPG in osteochondromas and peripheral chondrosarcomas. J Pathol 2007;211:399-409. 
36 Bovée JVMG, Sakkers RJ, Geirnaerdt MJ, et al. Intermediate grade osteosarcoma and chondrosarcoma arising in an osteochondroma. A case report of a patient with hereditary multiple exostoses. J Clin Pathol 2002;55:226-229.

37 Lamovec J, Spiler M, Jevtic V. Osteosarcoma arising in a solitary osteochondroma of the fibula. Arch Pathol Lab Med 1999;123:832-834.

38 Vanel D, Picci P, De Paolis $\mathrm{M}$, et al. Osteosarcoma arising in an exostosis: CT and MR imaging. AJR Am J Roentgenol 2001;176:259-260.

39 Nojima T, Yamashiro K, Fujita M, et al. A case of osteosarcoma arising in a solitary osteochondroma. Acta Orthop Scand 1991;62:290-292.

40 Gomez-Brouchet A, Accadbled F, Rubie H, et al. Rapid development of an osteosarcoma after surgical resection of an osteochondroma. J Pediatr Orthop 2007; 27:640-642.

41 Hameetman L, David G, Yavas A, et al. Decreased EXT expression and intracellular accumulation of heparan sulphate proteoglycan in osteochondromas and peripheral chondrosarcomas. J Pathol 2007;211:399-409.

42 Han C, Belenkaya TY, Khodoun M, et al. Distinct and collaborative roles of Drosophila EXT family proteins in morphogen signalling and gradient formation. Development 2004;131:1563-1575.

43 Takei Y, Ozawa Y, Sato M, et al. Three Drosophila EXT genes shape morphogen gradients through synthesis of heparan sulfate proteoglycans. Development 2004; 131:73-82.

44 Hameetman L, Kok P, Eilers PHC, et al. The use of Bcl2 and PTHLH immunohistochemistry in the diagnosis of peripheral chondrosarcoma in a clinicopathological setting. Virchows Arch 2005;446:430-437.

45 Rozeman LB, Hameetman L, Cleton-Jansen AM, et al. Absence of $\mathrm{IHH}$ and retention of PTHrP signalling in enchondromas and central chondrosarcomas. J Pathol 2005;205:476-482.
46 Romeo S, Bovée JVMG, Cleton-Jansen AM, et al. EXT pathways in chondromyxoid fibroma (CMF): immunohistochemical and gene expression approach. [abstract]. Mod Pathol 2004;17:18A.

47 Romeo S, Bovée JVMG, Grogan S, et al. Chondromyxoid fibroma resembles in vitro chondrogenesis, though differs in expression of signalling molecules. J Pathol 2005;206:135-142.

48 Hackel C, Czerniak B, Ayala AG, et al. Expression of plasminogen activators and plasminogen activator inhibitor 1 in dedifferentiated chondrosarcoma. Cancer 1997;79:53-58.

49 Dennler S, Itoh S, Vivien D, et al. Direct binding of Smad3 and Smad4 to critical TGF beta-inducible elements in the promoter of human plasminogen activator inhibitor-type 1 gene. EMBO J 1998; 17:3091-3100.

50 Song CZ, Siok TE, Gelehrter TD. Smad4/DPC4 and Smad3 mediate transforming growth factor-beta (TGFbeta) signaling through direct binding to a novel TGFbeta-responsive element in the human plasminogen activator inhibitor-1 promoter. J Biol Chem 1998; 273:29287-29290.

51 Dellas C, Loskutoff DJ. Historical analysis of PAI-1 from its discovery to its potential role in cell motility and disease. Thromb Haemost 2005;93:631-640.

52 Samarakoon R, Higgins CE, Higgins SP, et al. TGFbeta1-induced expression of the poor prognosis SERPINE1/PAI-1 gene requires EGFR signaling: a new target for anti-EGFR therapy. J Oncol 2009; 2009:342391.

53 Ray-Coquard I, Le Cesne A, Whelan JS, et al. A phase II study of gefitinib for patients with advanced HER-1 expressing synovial sarcoma refractory to doxorubicincontaining regimens. Oncologist 2008;13:467-473.

54 Ponta H, Sherman L, Herrlich PA. CD44: from adhesion molecules to signalling regulators. Nat Rev Mol Cell Biol 2003;4:33-45. 